\title{
A Patient with Localized Scleroderma Successfully Treated with Etretinate
}

\author{
Tomoko Shima Yuki Yamamoto Takaharu Ikeda Fukumi Furukawa \\ Department of Dermatology, Wakayama Medical University, Wakayama, Japan
}

\section{Key Words}

Localized scleroderma $\cdot$ Etretinate $\cdot$ Treatment

\begin{abstract}
There are several treatment methods for localized scleroderma, but treatment is difficult when the lesion is widely distributed. We encountered a case who was treated successfully with etretinate, a vitamin A derivative. The usefulness of this agent is discussed.
\end{abstract}

(C) 2014 S. Karger AG, Basel

\section{Introduction}

There are several treatment methods for localized scleroderma, but treatment is difficult when the lesion is widely distributed. Systemic scleroderma cases in whom vitamin A derivatives are effective for skin sclerotic lesions are reported in the literature $[1,2]$. We encountered a patient with localized scleroderma in whom a vitamin A derivative, etretinate [ethyl (2E, 4E, 6E, 8E)-9-(4-methoxy-2,3,6-trimethylphenyl)-3,7-dimethyl-2,4,6,8nonatetraenoate], was effective for skin sclerosis, and we report this case briefly herein.

\section{Case Report}

A 28-year-old female presented because of brown pigmentation and sclerosis of the right lower limb. She had a past medical history of Caesarean sections (at 22 and 24 years), without particular familial medical history. The history of current illness was as follows: She noticed brown pigmentation of the right thigh in 2008. It gradually expanded to her right lower back, but there was no tenderness, spontaneous pain or pruritus. The patient visited a 
dermatologist and was administered a vitamin C preparation, but it was ineffective for treating the pigmented lesion. Since sclerosis developed in the pigmented region along the course, the patient visited our clinic in September 2011. Upon first examination, brown pigmentation with a slightly clear boundary was present on the right thigh and crus (fig. 1). No general symptoms, such as Raynaud's phenomenon, were noted.

Her serum IgG level was $1,764 \mathrm{mg} / \mathrm{dl}$, and antinuclear antibody titers (FA method) were 160 times, which was slightly elevated, but no specific autoantibody was detected, and no other abnormal findings were noted. For histopathological examination, biopsy specimens were collected from two sites: (1) In the sclerotic region (fig. 2a), flattened epidermis and increased collagen fibers directly below the epidermis over the deep dermis were noted, and appendages, such as sweat glands, had been lost. (2) In the pigmented region (fig. 2b), the sweat glands and adipose tissue had been excluded by increased collagen fibers. Under high magnification, many infiltrating inflammatory cells were noted around sweat glands, vessels, and adipose tissue in the deep dermis. On Fontana-Masson staining, melanin deposits were noted throughout the epidermal layer in the pigmented region.

Based on clinical and histopathological findings, the patient was diagnosed with localized scleroderma. Oral treatment with etretinate $20 \mathrm{mg} /$ day was initiated. The reasons for etretinate selection were that she did not want more children and that acitretin or isotretinoin are not approved in Japan. The skin sclerosis started to improve 28 days after treatment initiation. Oral treatment was continued for about 5 months, and the skin sclerosis and pigmentation improved. Topical corticosteroids were not administered during this period, and no adverse events, such as pruritus, skin thinning, gastroenteritis, paronychia or angular cheilitis, developed. 15 months after the discontinuation of etretinate treatment, although the brown pigmentation remained, improvements in skin eruption were maintained compared to those upon first examination (fig. 3).

Biopsy results upon first examination, after 4 months of oral treatment and 9 months after discontinuation of oral treatment were compared (fig. 4). Under low magnification, epidermal thickening was noted after 4 months of oral treatment and 9 months after treatment discontinuation, and sweat glands were present in the dermis. In addition, collagen fibers in the dermis had become bulky and dense (fig. 4). Under high magnification, infiltrating inflammatory cells around vessels and in lobular fat in the deep dermis had decreased and atrophied appendages had recovered.

\section{Discussion}

The localized scleroderma in this patient was categorized as linear scleroderma because linear or belt-like skin sclerosis accompanied by the pigmented region and concavity was observed.

A variety of treatment options are available for patients with active lesions of localized scleroderma; however, evidence in support of many of these therapies is limited. For superficial and localized forms, topical treatments are done, such as tacrolimus and highpotency corticosteroids, or phototherapies with narrow-band UVB, UVB, UVA or UVA-1 are performed. For deep and/or generalized types, including sclerodermatous graft-versus-host disease and eosinophilic fasciitis, systemic administrations of corticosteroids and immunosuppressant therapies are administered in combination with topical treatments and phototherapies [3-6]. Although these are effective, their use or continuation may be difficult due to tolerability or adverse reactions in some cases. 
Etretinate is a vitamin A derivative and as such, the possibility of teratogenic adverse reactions (during pregnancy) cannot be ruled out. However, it is used to treat psoriasis and palmoplantar pustulosis in Japan, and adverse reactions include hyperlipidemia, cheilitis and hair loss. As advantages, complications such as infection sensitivity induced by corticosteroids and immunosuppressors do not develop. The drug has recently been used to treat systemic scleroderma [7].

The usefulness of retinoids (retinoic acid) in treating skin sclerosis of systemic scleroderma has been reported in the literature [1, 2, 7]. Retinoids decrease collagen synthesis [8]. Although the number of reported cases of localized scleroderma treated with oral etretinate is small, it is thought that collagen synthesis inhibition and apoptosis of overgrowing fibroblasts and inflammatory cells are plausible as pathomechanisms $[9,10]$.

\section{References}

1 Bahmer FA, Zaun H: Isotretinoin therapy for progressive systemic sclerosis. Arch Dermatol 1985;121:308.

2 Mizutani H, Yoshida T, Nouchi N, Hamanaka H, Shimizu M: Topical tocoretinate improved hypertrophic scar, skin sclerosis in systemic sclerosis and morphea. J Dermatol 1999;26:11-17.

-3 Maurice PD, Bunker CB, Dowd PM: Isotretinoin in the treatment of systemic sclerosis. Br J Dermatol 1989;121:367-374.

4 Ozdemir M, Engin B, Toy H, Mevlitoglu I: Treatment of plaque-type localized scleroderma with retinoic acid and ultraviolet A plus the photosensitizer psoralen: a case series. J Eur Acad Dermatol Venereol 2008;22: 519-521.

5 Ghoreschi K, Thomas P, Penovici M, Ullmann J, Sander CA, Ledderose G, Plewig G, Kolb HJ, Röcken M: PUVA-bath photochemotherapy and isotretinoin in sclerodermatous graft-versus-host disease. Eur J Dermatol 2008;18:667-670.

6 Weber HO, Schaller M, Metzler G, Röcken M, Berneburg M: Eosinophilic fasciitis and combined UVA1retinoid-corticosteroid treatment: two case reports. Acta Derm Venereol 2008;88:304-306.

7 Ikeda T, Uede K, Hashizume H, Furukawa F: The Vitamin A derivative etretinate improves skin sclerosis in patients with systemic sclerosis. J Dermatol Sci 2004;34:62-66.

8 Delany AM, Brinckerhoff CE: The synthetic retinoid (4-hydroxyphenyl)retinamide decreases collagen expression in vitro and in the tight-skin mouse. Arthritis Rheum 1993;36:983-993.

-9 Ikeda T, Nishide T, Ohtani T, Furukawa F: The effects of vitamin A derivative etretinate on the skin of MRL mice. Lupus 2005;14:510-516.

10 Ikeda T, Ohtani T, Furukawa F: Vitamin A derivative etretinate improves bleomycin-induced scleroderma. Allergol Int 2005;54:419-425. 
Shima et al.: A Patient with Localized Scleroderma Successfully Treated with Etretinate

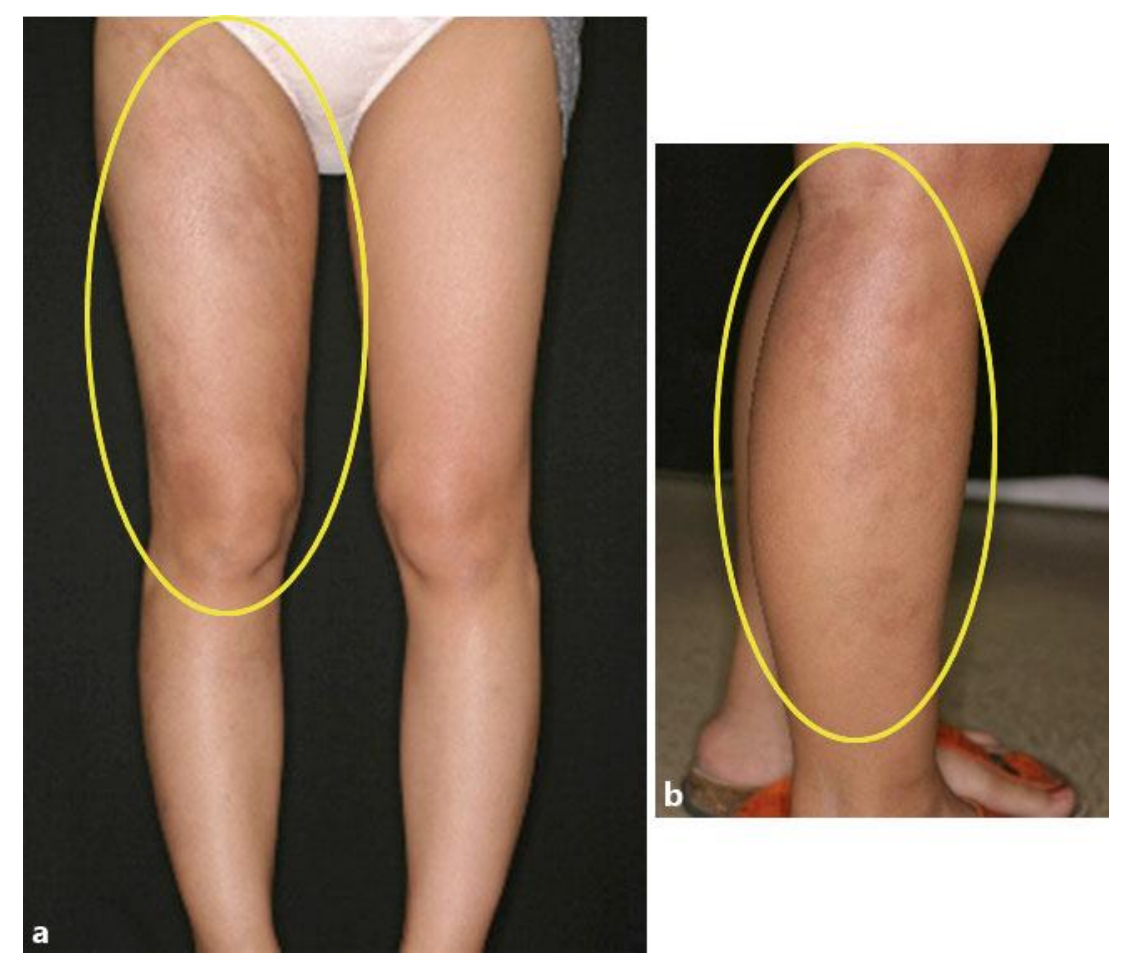

Fig. 1. Skin symptoms upon first examination. Sclerosis of the right thigh (a) and crus (b) with a slightly clear boundary accompanied by brown pigmentation. 
Shima et al.: A Patient with Localized Scleroderma Successfully Treated with Etretinate
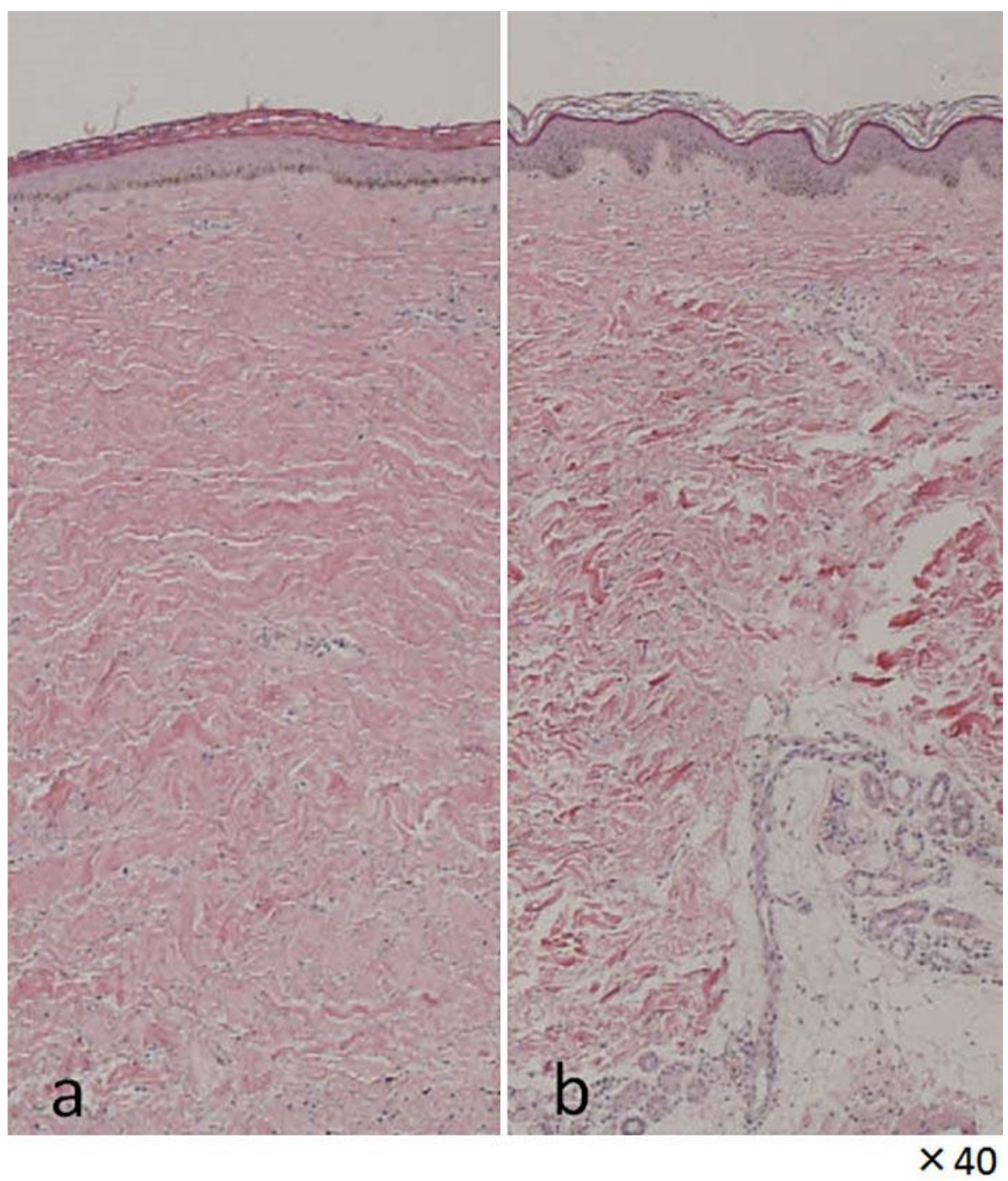

Fig. 2. Histopathology. a Sclerotic region. b Pigmented region. 


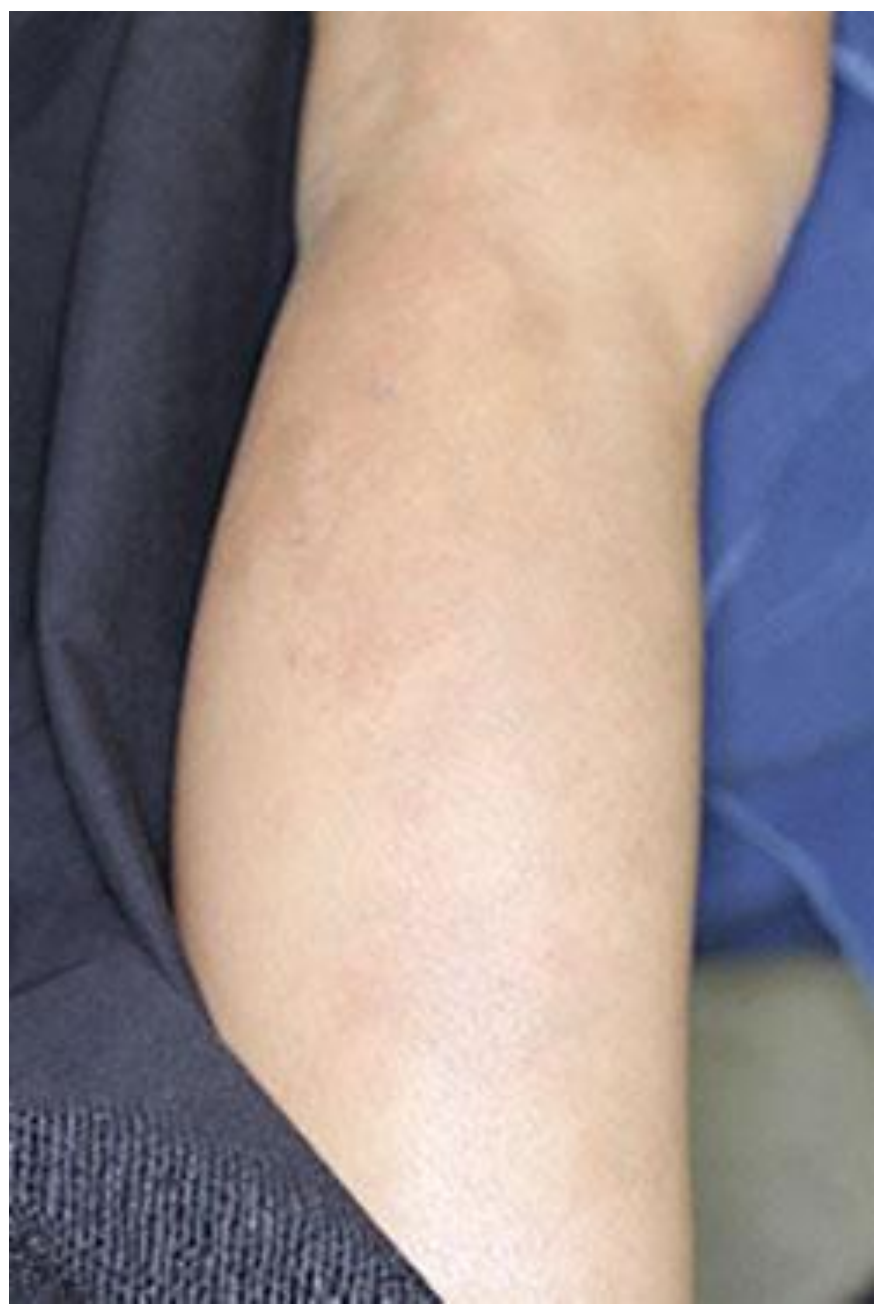

Fig. 3. Clinical findings 15 months after the discontinuation of etretinate treatment. 


\section{Case Reports in Dermatology}

\begin{tabular}{l|l}
\hline Case Rep Dermatol 2014;6:200-206 \\
\hline DOI: 10.1159/000367707 & $\begin{array}{l}\text { C 2014 S. Karger AG, Basel } \\
\text { www.karger.com/cde }\end{array}$ \\
\hline
\end{tabular}

Shima et al.: A Patient with Localized Scleroderma Successfully Treated with Etretinate
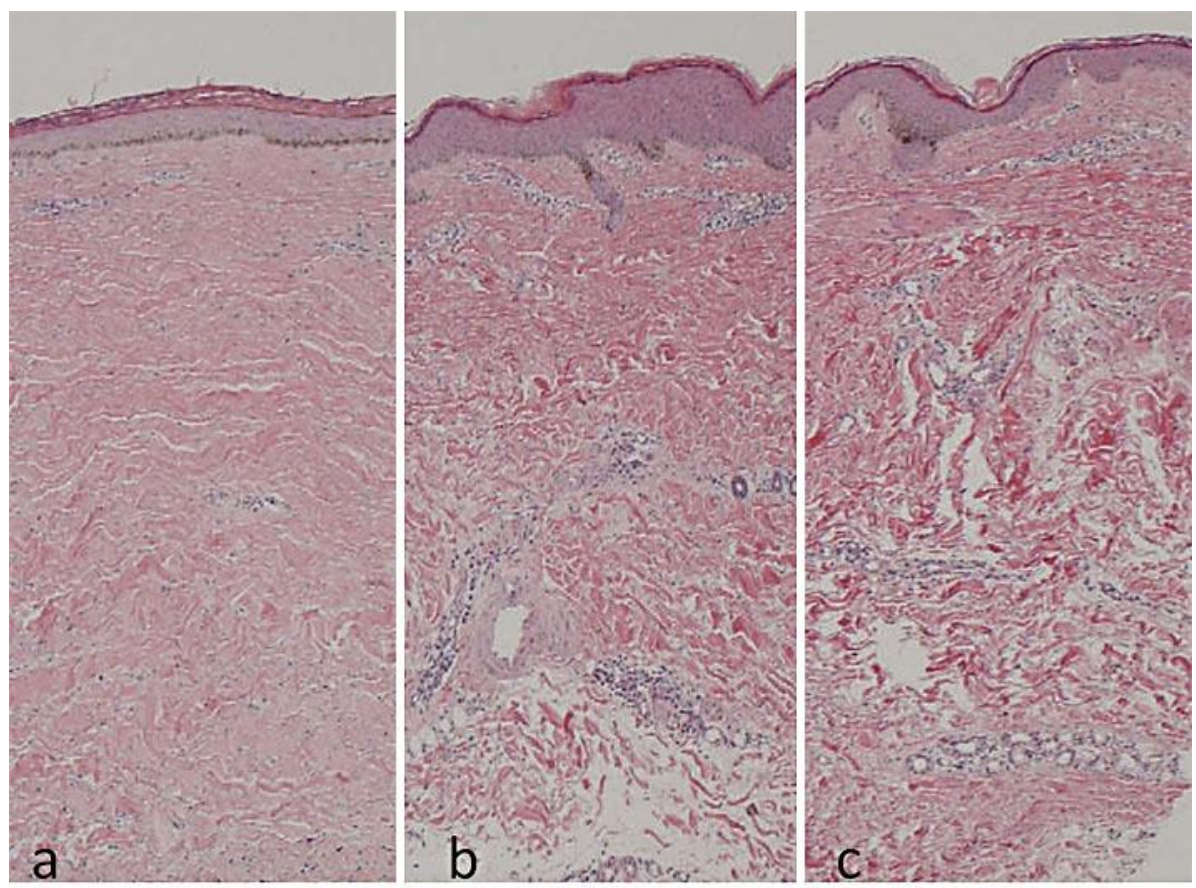

$\times 40$

Fig. 4. Histological changes in the sclerotic region. a On first examination. b After 4 months of oral etretinate treatment. c 9 months after discontinuation of etretinate treatment. 